\title{
Chapter 4 \\ Reduction of Cytochrome $c$ Oxidase \\ During Vasovagal Hypoxia-Ischemia in Human Adult Brain: A Case Study
}

\author{
Arnab Ghosh, Christina Kolyva, Ilias Tachtsidis, David Highton, \\ Clare E. Elwell, and Martin Smith
}

\begin{abstract}
Near-infrared spectroscopy (NIRS)-derived measurement of oxidized cytochrome $c$ oxidase concentration ([oxCCO]) has been used as an assessment of the adequacy of cerebral oxygen delivery. We report a case in which a reduction in conscious level was associated with a reduction in [oxCCO]. Hypoxaemia was induced in a 31-year-old, healthy male subject as part of an ongoing clinical study. Midway through the hypoxaemic challenge, the subject experienced an unexpected vasovagal event with bradycardia, hypotension and reduced cerebral blood flow (middle cerebral artery blood flow velocity decrease from 70 to $30 \mathrm{~cm} \mathrm{~s}^{-1}$ ) that induced a brief reduction in conscious level. An associated decrease in [oxCCO] was observed at $35 \mathrm{~mm}(-1.6 \mu \mathrm{M})$ but only minimal change $(-0.1 \mu \mathrm{M})$ at $20-\mathrm{mm}$ source-detector separation. A change in optical scattering was observed, but path length remained unchanged. This unexpected physiological event provides an unusual example of a severe reduction in cerebral oxygen delivery and is the first report correlating change in clinical status with changes in [oxCCO].
\end{abstract}

The original version of this chapter was revised. An erratum to this chapter can be found at https://doi.org/10.1007/978-1-4614-7411-1_63

A. Ghosh $(\varangle) \cdot$ D. Highton

Neurocritical Care Unit, University College Hospitals, WC1N 3BG London, UK

e-mail: arnab.ghosh@ucl.ac.uk

C. Kolyva $\bullet$ I. Tachtsidis $\bullet$ C.E. Elwell

Medical Physics \& Bioengineering, University College London WC1E 6BT London, UK

M. Smith

Neurocritical Care Unit, University College Hospitals, WC1N 3BG London, UK

Medical Physics \& Bioengineering, University College London, WC1E 6BT London, UK

S. Van Huffel et al. (eds.), Oxygen Transport to Tissue XXXV, Advances

in Experimental Medicine and Biology 789, DOI 10.1007/978-1-4614-7411-1_4,

(C) The Author(s) 2013 


\subsection{Introduction}

Cytochrome $c$ oxidase is the final electron acceptor in the mitochondrial electron transport chain, and its oxidation state, measured by NIRS as [oxCCO], has thus been proposed as a marker of the adequacy of cerebral oxygen delivery $\left(\mathrm{DO}_{2}\right)$ [1]. However, prior studies of moderate hypoxia achieved only modest reductions in $\mathrm{DO}_{2}$, leaving the relationship between $\mathrm{DO}_{2}$ and $\Delta$ [oxCCO] unclear [2]. Furthermore, interpretation of [oxCCO] measurements is difficult as there are no adult human data regarding its total concentration or resting oxidation state.

We aimed to address some of these concerns with studies using a hybrid NIR spectrometer, the $\mathrm{pHOS}$, to measure [oxCCO] and other optical parameters whilst modulating $\mathrm{DO}_{2}$ in a cohort of healthy volunteers [3]. We report the case of a vasovagal event that occurred during one such study and explore the insights into cerebral physiology gleaned from this unexpected event.

\subsection{Methods}

A single case was selected from a larger group study. This study was approved by the Institutional Research Ethics Committee, and written informed consent was provided by the subject, a 31-year-old male who had been screened for pre-existing medical conditions, was selected as he suffered from vasovagal pre-syncope during a challenge that comprised induction of isocapnic hypoxia with a target arterial oxygen saturation $\left(\mathrm{SpO}_{2}\right)$ of $80 \%$ [3].

The pHOS, described in more detail elsewhere [4], combines frequency domain (FD) and broadband (BB) components. Changes in chromophore concentration were estimated by using the changes in light attenuation as measured by the BB spectrometer, using the UCLn algorithm to resolve for three chromophores - oxyhaemoglobin $\left(\mathrm{HbO}_{2}\right)$, deoxyhaemoglobin $(\mathrm{HHb})$ and oxCCO - between 780 and $900 \mathrm{~nm}$. A fixed differential path length factor (DPF) of 6.26 [5] was used to enable comparison with previous studies. The FD component measured the absolute absorption and scattering coefficients ( $\mu \mathrm{a}$ and $\mu \mathrm{s}$, respectively) at discrete wavelengths 690, 750, 790 and $850 \mathrm{~nm}$, allowing the estimation of DPF at each of these wavelengths using the diffusion approximation [6]. The pHOS optode was placed over the FP1 point on the right side of the forehead.

Other monitoring included beat-to-beat $\mathrm{SpO}_{2}$, continuous non-invasive arterial blood pressure, and transcranial Doppler (TCD) ultrasonography was used to measure middle cerebral artery flow velocity (Vmca), insonating through the right temporal window, ipsilateral to pHOS monitoring. Estimated relative cerebral oxygen delivery $\left(\mathrm{ecOO}_{2}\right)$ was calculated as the product of changes in $\mathrm{SpO}_{2}$ and Vmca (relative to their initial values) [2]. Synchronization between the pHOS and other 
monitors was performed by means of a signal voltage output by the frequency domain spectrometer for the length of recording; all data were resampled to a sample period of $3.2 \mathrm{~s}$ across the length of recording. Twenty-second data windows were selected for the reporting of summary data. Changes in hemoglobin species concentration are expressed as total hemoglobin $\left(\Delta[\mathrm{HbT}]=\Delta\left[\mathrm{HbO}_{2}\right]+\Delta[\mathrm{HHb}]\right)$ and hemoglobin difference $\left(\Delta[\mathrm{HbDiff}]=\Delta\left[\mathrm{HbO}_{2}\right]-\Delta[\mathrm{HHb}]\right)$. All analysis was carried out in Matlab® 2011b.

\subsection{Results}

Approximately $600 \mathrm{~s}$ after the commencement of recording, during the nadir of hypoxia, the subject suffered from sudden-onset bradycardia and hypotension (a typical vasovagal episode), resulting in a reduction in $\mathrm{ecDO}_{2}$ to $41.5 \%$ of baseline values (Table 4.1 and Fig. 4.1). During this time, the subject became briefly unresponsive. When this occurred, he was laid flat and the breathing circuit replaced with a Mapleson $\mathrm{C}$ circuit delivering high-flow oxygen.

Hemoglobin species showed a consistent pattern of change with a decrease in both [HbT] and [HbDiff] seen at all source-detector separations (Fig. 4.2). By contrast, [oxCCO] showed a source-detector separation-dependent decrease ( $\Delta[\mathrm{oxCCO}]-1.6 \mu \mathrm{M}$ at $3.5 \mathrm{~cm}$ c.f. $-0.1 \mu \mathrm{M}$ at $2.0-\mathrm{cm}$ source-detector separation), with larger decreases seen at further source-detector separations (Fig. 4.3). Comparison of $\Delta$ [oxCCO] (observed at the 3.5 -cm detector) with $\Delta \mathrm{ecDO}_{2}$ suggests a linear relationship (Fig. 4.4) between the two variables $\left(r^{2}=0.81, p<0.001\right)$. There appeared to be a roughly $10 \%$ decrease in the $\mu$ s observed at all four discrete wavelengths, but this did not translate into an apparent change in DPF (Fig. 4.5).

Table 4.1 Mean values of systemic and cerebral physiological parameters observed during four observed phases

\begin{tabular}{|c|c|c|c|c|c|}
\hline & & Baseline & Hypoxia & Hypoxia-ischemia & Recovery \\
\hline$\overline{\mathrm{ABP}}(\mathrm{mmHg})$ & & 85.4 & 88.9 & 32.1 & 83.5 \\
\hline HR & & 78.0 & 117 & 41.3 & 101 \\
\hline Vmca $\left(\mathrm{cm} \mathrm{s}^{-1}\right)$ & & 70.4 & 73.9 & 34.1 & 57.8 \\
\hline $\mathrm{SpO}_{2}(\%)$ & & 100 & 72.6 & 86.3 & 99.4 \\
\hline $\operatorname{ecDO}_{2}(\%)$ & & 99.8 & 75.8 & 41.5 & 81.2 \\
\hline \multirow[t]{4}{*}{$\Delta[0 x \mathrm{CCO}](\mu \mathrm{M})$} & $3.5 \mathrm{~cm}$ & 0 & -0.74 & -1.56 & -0.13 \\
\hline & $3.0 \mathrm{~cm}$ & 0 & -0.38 & -0.62 & 0.008 \\
\hline & $2.5 \mathrm{~cm}$ & 0 & -0.30 & -0.55 & 0.045 \\
\hline & $2.0 \mathrm{~cm}$ & 0 & -0.14 & -0.16 & 0.23 \\
\hline
\end{tabular}




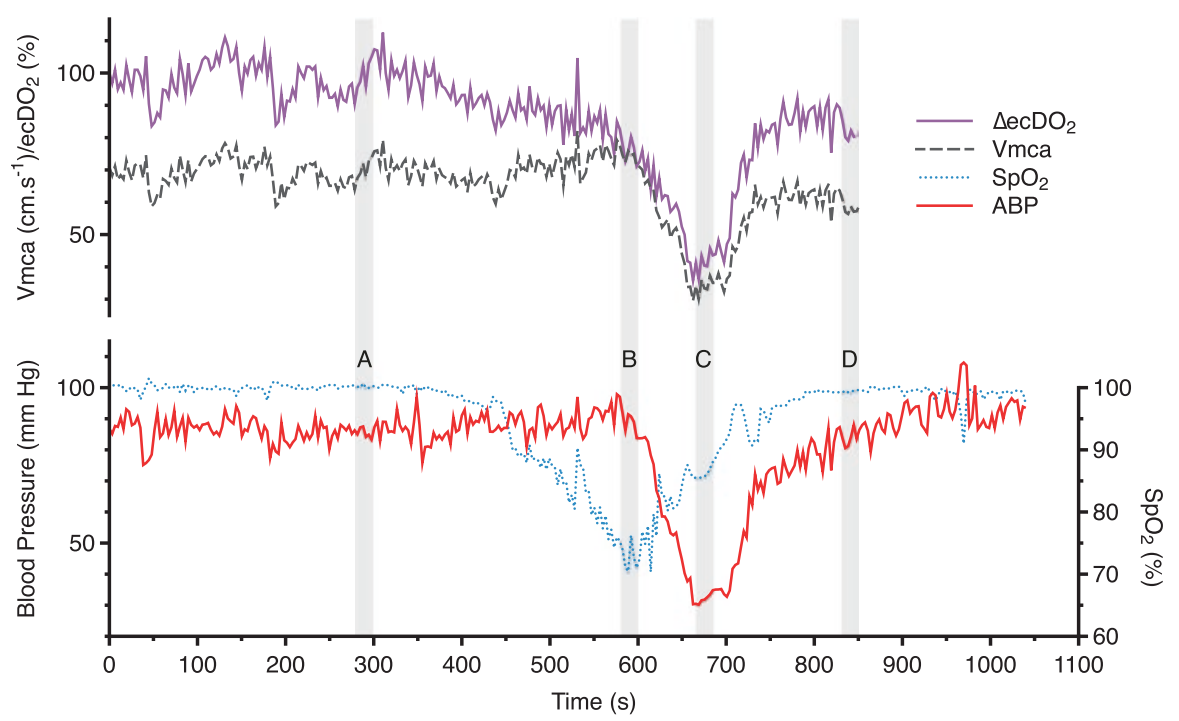

Fig. 4.1 Changes in systemic and physiological parameters. Data averaging periods $A$ baseline, $B$ hypoxia, $C$ hypoxia-ischemia, $D$ recovery
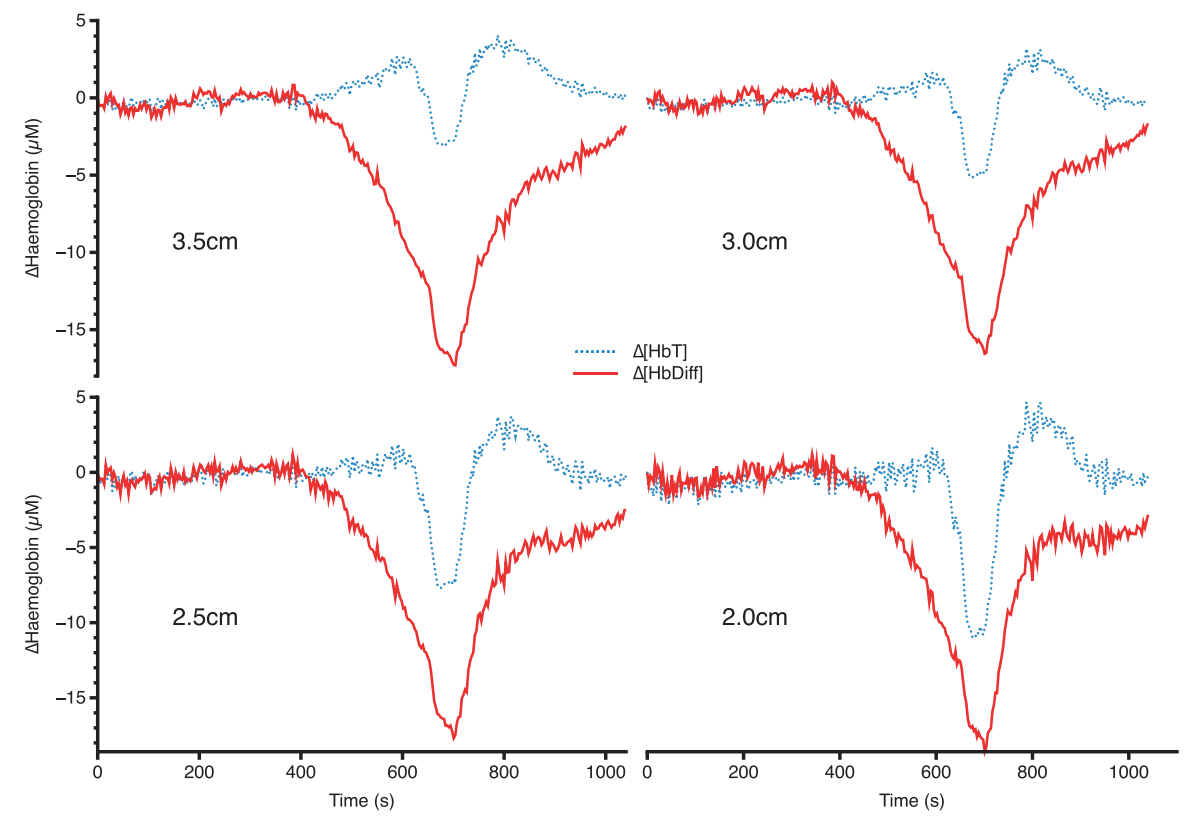

Fig. 4.2 Changes in hemoglobin concentrations at four source-detector separations 
4 Reduction of Cytochrome $c$ Oxidase During Vasovagal Hypoxia-Ischemia...
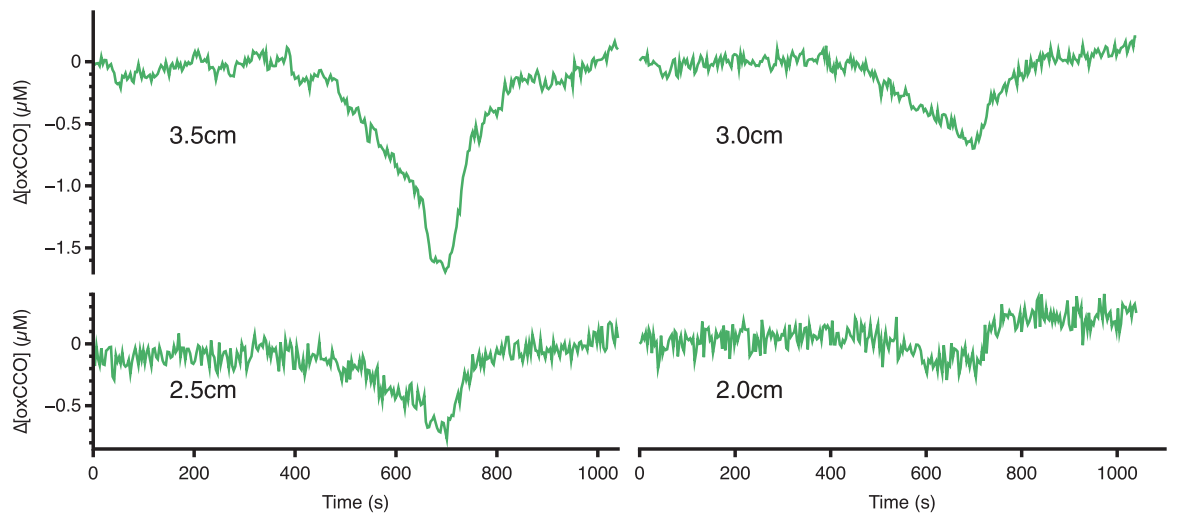

Fig. 4.3 Changes in [oxCCO] at four source-detector separations

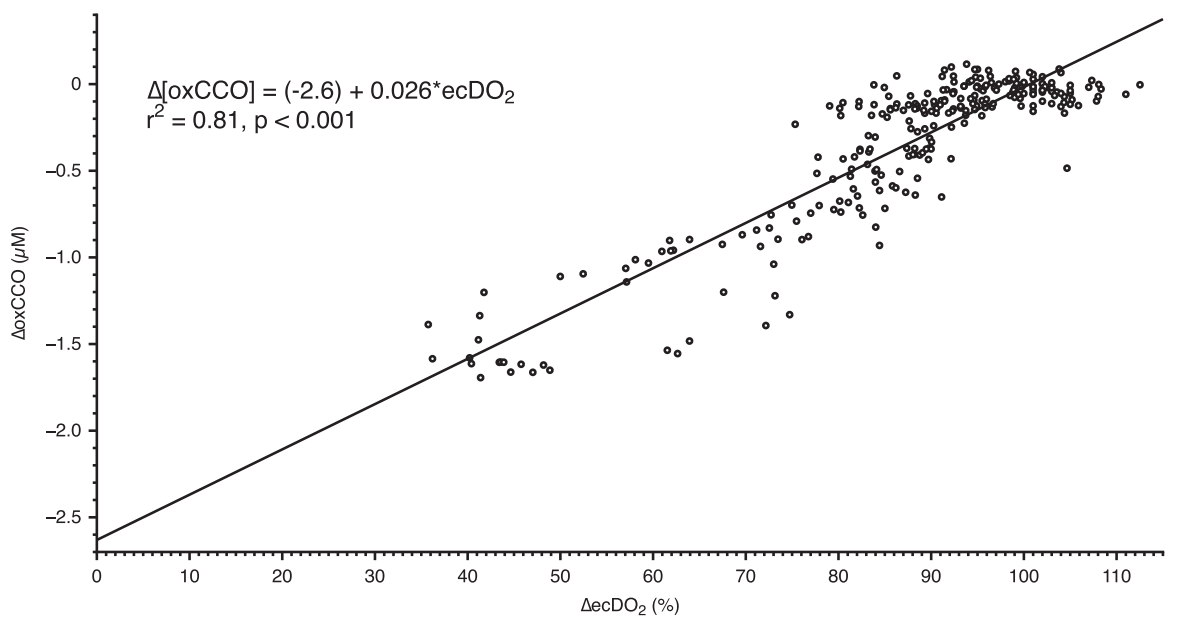

Fig. 4.4 Relationship between $\mathrm{eDO}_{2}$ and $\Delta[\mathrm{oxCCO}]$ at $3.5 \mathrm{~cm}$ source-detector separation

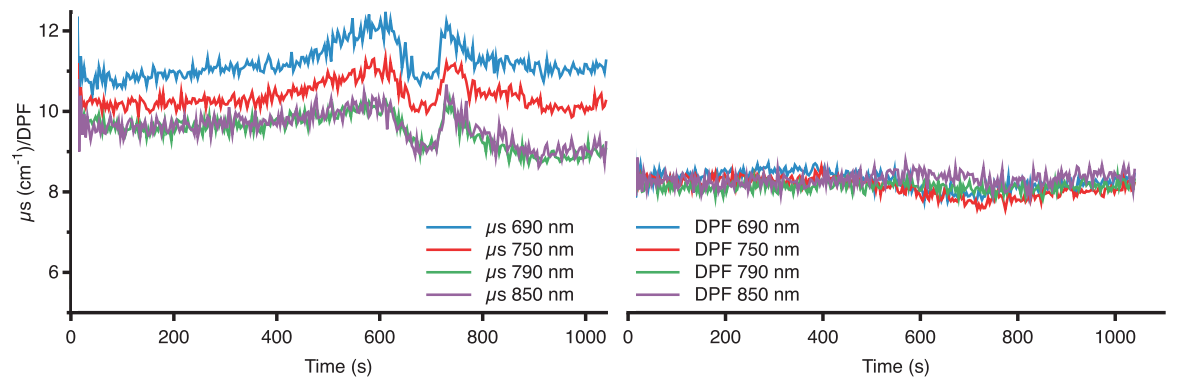

Fig. 4.5 Changes in $\mu$ s and DPF 


\subsection{Discussion}

We report a reduction in cranial [oxCCO] measured with the $\mathrm{pHOS}$ during a vasovagal pre-syncope in a healthy adult volunteer. This reduction was larger in further $(3.5 \mathrm{~cm})$ than closer $(2.0 \mathrm{~cm})$ source-detector separations. The pattern of [oxCCO] reduction has been related to neurological outcome following cardiopulmonary bypass [7], and asymptomatic reductions in [oxCCO] have been reported during moderate hypoxia [2], but this is the first change in [oxCCO] to be correlated to changes in conscious level and the largest change to be reported in humans.

Whilst hypoxia is a recognized cause of syncope, the occurrence of bradycardia and hypotension indicates a vasovagal etiology [8], in this case, provoked by - as the subject reported - the shock of seeing his reduced $\mathrm{SpO}_{2}$ reading. This vasovagal response resulted in a profound reduction in cerebral blood flow (observed by both NIRS and TCD), and this led to a significant reduction in $\mathrm{DO}_{2}$.

Prior experiments have achieved only modest reductions in $\mathrm{DO}_{2}$, leaving questions unanswered about the relationship between $\mathrm{DO}_{2}$ and $\Delta$ [oxCCO] [2]. In particular, it was unclear whether the relationship between $\mathrm{DO}_{2}$ and $\Delta$ [oxCCO] was linear or whether there was a $\mathrm{DO}_{2}$ threshold below which rapid $\mathrm{CCO}$ reduction occurs. However, our data (Fig. 4.4) suggest a linear relationship between $\Delta$ [oxCCO] and $\Delta \mathrm{ecDO}_{2}\left(r^{2}=0.81, p<0.001\right)$. From this, the extrapolated value of $\Delta[\mathrm{oxCCO}]$ of $-2.6 \mu \mathrm{M}$ with zero cerebral oxygen delivery is suggestive of a resting oxidized $\mathrm{CCO}$ concentration of around $2.6 \mu \mathrm{M}$. Although no reduction of this size has been reported in humans - understandably as a reduction in $\mathrm{DO}_{2}$ to nothing is impractical in humans - these values are consistent with animal anoxia models [9, 10].

Given the distance dependence of the [oxCCO] but not hemoglobin changes, we consider spectral crosstalk to be unlikely. Similarly, the modest $\mu$ s changes that were observed appeared consistent in their spectral expression across 690-850 nm and thus are unlikely to account for the [oxCCO] changes seen. DPF showed no significant qualitative change during the hypoxic or ischaemic phases of the study, although the absolute values were larger than those that were previously reported [5]; using the measured values of DPF rather than the fixed value of 6.26 would thus change the magnitude, but not the qualitative profile of our observed chromophore changes.

Whilst we are aware of the limitations of extrapolating from a single case report, these data, especially when considered in conjunction with the results of the larger cohort of (uncomplicated!) hypoxia and hypercapnia studies [3], further underline confidence in the ability to use NIRS to measure [oxCCO] as a marker of cellular energy status.

Acknowledgments This work was undertaken at University College London Hospitals and partially funded by the Department of Health's National Institute for Health Research Centers funding scheme, the Medical Research Council and Wellcome Trust. 


\section{References}

1. Smith M, Elwell C (2009) Near-infrared spectroscopy: shedding light on the injured brain. Anesth Analg 108(4):1055-1057

2. Tisdall MM, Tachtsidis I, Leung TS, Elwell CE, Smith M (2007) Near-infrared spectroscopic quantification of changes in the concentration of oxidized cytochrome c oxidase in the healthy human brain during hypoxemia. J Biomed Opt 12(2):024002

3. Kolyva C, Ghosh A, Tachtsidis I, et al (2013) Dependence on NIRS source-detector spacing of cytochrome $\mathrm{C}$ oxidase response to hypoxia and hypercapnia in the adult brain. Adv Exp Med Biol.

4. Kolyva C, Tachtsidis I, Ghosh A et al (2012) Systematic investigation of changes in oxidized cerebral cytochrome $\mathrm{c}$ oxidase concentration during frontal lobe activation in healthy adults. Biomed Opt Express 3(10):2550-2566

5. Duncan A, Meek JH, Clemence M et al (1995) Optical pathlength measurements on adult head, calf and forearm and the head of the newborn infant using phase resolved optical spectroscopy. Phys Med Biol 40(2):295-304

6. Arridge SR, Cope M, Delpy DT (1992) The theoretical basis for the determination of optical pathlengths in tissue: temporal and frequency analysis. Phys Med Biol 37(7):1531-1560

7. Kakihana Y, Matsunaga A, Yasuda T, Imabayashi T, Kanmura Y, Tamura M (2008) Brain oxymetry in the operating room: current status and future directions with particular regard to cytochrome oxidase. J Biomed Opt 13(3):033001

8. Chen-Scarabelli C, Scarabelli TM (2004) Neurocardiogenic syncope. Br Med J 329(7461): 336-341

9. Cooper CE, Cope M, Springett R et al (1999) Use of mitochondrial inhibitors to demonstrate that cytochrome oxidase near-infrared spectroscopy can measure mitochondrial dysfunction noninvasively in the brain. J Cereb Blood Flow Metab 19(1):27-38

10. Cooper CE, Springett R (1997) Measurement of cytochrome oxidase and mitochondrial energetics by near-infrared spectroscopy. Philos Trans R Soc Lond B Biol Sci 352(1354): 669-676

Open Access This chapter is licensed under the terms of the Creative Commons Attribution 4.0 International License (http://creativecommons.org/licenses/by/4.0/), which permits use, sharing, adaptation, distribution and reproduction in any medium or format, as long as you give appropriate credit to the original author(s) and the source, provide a link to the Creative Commons license and indicate if changes were made.

The images or other third party material in this chapter are included in the chapter's Creative Commons license, unless indicated otherwise in a credit line to the material. If material is not included in the chapter's Creative Commons license and your intended use is not permitted by statutory regulation or exceeds the permitted use, you will need to obtain permission directly from the copyright holder.

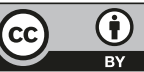

